Post-print of: Eur Biophys J (2011) 40:1301-1315

\title{
Cytochrome c signalosome in mitochondria
}

Irene Díaz-Moreno (1), José M. García-Heredia (1), Antonio Díaz-Quintana (1) and Miguel A. De la Rosa (1)

(1) Instituto de Bioquímica Vegetal y Fotosíntesis, Centro de Investigaciones Científicas Isla de la Cartuja (cicCartuja), Universidad de Sevilla-CSIC, Avda. Américo Vespucio 49, 41092 Sevilla, Spain

\begin{abstract}
Cytochrome c delicately tilts the balance between cell life (respiration) and cell death (apoptosis). Whereas cell life is governed by transient electron transfer interactions of cytochrome $\mathrm{c}$ inside the mitochondria, the cytoplasmic adducts of cytochrome $\mathrm{c}$ that lead to cell death are amazingly stable. Interestingly, the contacts of cytochrome $c$ with its counterparts shift from the area surrounding the heme crevice for the redox complexes to the opposite molecule side when the electron flow is not necessary. The cytochrome c signalosome shows a higher level of regulation by post-translational modifications-nitration and phosphorylation-of the hemeprotein. Understanding protein interfaces, as well as protein modifications, would puzzle the mitochondrial cytochrome c-controlled pathways out and enable the design of novel drugs to silence the action of pro-survival and pro-apoptotic partners of cytochrome c.
\end{abstract}

\section{Keywords}

Biointeractome, Cytochrome c, Transient complex, Electron transfer, Mitochondria, Signalosome

\section{Abbreviations}

$\operatorname{Adx}$

Adrenodoxin

$\operatorname{AdxR}$

NADPH-dependent adrenodoxin reductase

bc 1

Cytochrome bc 1 complex

$\mathrm{CB}$

Cytochrome binding 
$\mathrm{Cb} 5$

Cytochrome b 5

$\mathrm{Cb} 5 \mathrm{R}$

NADH-dependent cytochrome b 5 reductase

Cc

Cytochrome c

Cc 552

Cytochrome c 552

$\mathrm{CcO}$

Cytochrome c oxidase

$\mathrm{CcP}$

Cytochrome c peroxidase

$\mathrm{CH} 1$

Collagen homologous 1

$\mathrm{CH} 2$

Collagen homologous 2

$\mathrm{CL}$

CardioLipin

ET

Electron transfer

GALDH

I-GAlactono-1,4-Lactone DeHydrogenase

IMM

Inner mitochondrial membrane

IMS

Intermembrane mitochondrial space

$\mathrm{n}-\mathrm{Cc}$ 
Nitrated cytochrome c

NMR

Nuclear magnetic resonance

OMM

Outer mitochondrial membrane

$\mathrm{p}-\mathrm{Cc}$

Phosphorylated cytochrome c

PCD

Programmed cell death

PKC $\beta$

Protein kinase $C \beta$

PKC $\delta$

Protein kinase $\mathrm{C} \delta$

PRE

Paramagnetic relaxation enhancement

PTB

PhosphoTyrosine binding

$\mathrm{R}(\mathrm{N}) \mathrm{OS}$

Reactive (nitrogen)oxygen species

Sco

Synthesis of cytochrome c oxidase

$\mathrm{SH} 2$

Src homology 2

WT

Wild-type

Cytochrome c: a multitasking post-translationally modified protein 
Cells must be considered as a crowded system, in which any particular protein may be in contact with lots of other proteins, nucleic acids, metabolites, etc. It thus requires a way of recognition that allows the specific interaction with only a few of them. Such recognition mechanisms between biomolecules occur in a wide range of time scales. On one hand, stable complexes, with a lifetime ranging from minutes to days, involve high affinity and high specificity binding. On the other, weak complexes, with a lifetime within the $s-\mu s$ range, are formed when a fine balance between specificity of binding and high turnover rate is sought, resulting in adducts with equilibrium dissociation constants in the $\mu \mathrm{M}$ or even $\mathrm{mM}$ range (Ubbink 2009; Bashir et al. 2011; Díaz-Moreno and De la Rosa 2011a, b). Intriguingly, contrary to what one might think, these molecular recognition mechanisms are not uncommon, being crucial in electron transfer (ET) chains-such as respiration, peroxidation and steroid hormone biosynthesis.

Both types of complexes-stable versus weak-meet on cytochrome c (Cc), which is an excellent model: $\mathrm{Cc}$ is not only able to form protein adducts with different lifetimes, but is also a highly conserved protein along evolution. $\mathrm{Cc}$ is a small soluble metalloprotein of around 12.5 $\mathrm{kDa}$ located at the intermembrane mitochondrial space (IMS). It folds in four $\alpha$-helices and two extended loops, which sandwich on the heme group and provide its two axial ligands, His18 and Met80 (Louie and Brayer 1990; Reincke et al. 2001; Jeng et al. 2002). The porphyrin ring is covalently bound to the cysteine residues of the $\mathrm{CXXCH}$ motif and partially exposed to solvent, a feature that is essential for Cc to carry out most of its functions.

Under physiological, non-stressed conditions, Cc plays a key role in energy metabolism by a controlled redox interaction with its counterparts in the mitochondrial respiratory chain (Moore and Pettigrew 1990). Shuttling electrons between the two membrane-bound protein complexes cytochrome bc 1 (bc 1 ) and cytochrome c oxidase ( $\mathrm{CcO}$ ) requires rapid adduct formation and rapid protein dissociation, as well as a proper and efficient orientation of the two proteins of the transient complex to optimize the ET.

Upon an apoptotic signalling stimulus due to DNA damage or an excess in Reactive (Nitrogen)Oxygen Species (R(N)OS), the cells may undergo disturbances of their regulatory pathways that lead to the release of mitochondrial $\mathrm{Cc}$. Although $\mathrm{Cc}$ is preferably reduced in the cytosol, the interaction with Apaf-1 is independent of its redox state. The Cc/Apaf-1 complex forms the apoptosome, which is the enzymatic machinery of apoptosis (Cai et al. 1998; Orrenius 2007). Thus, the apoptosome is the result of stable and long-lived interactions of CC with other protein partners (Acehan et al. 2002).

Cell life is governed by transient interactions of $\mathrm{Cc}$ inside the mitochondria, but the cytoplasmic adducts of $\mathrm{Cc}$ that lead to cell death are amazingly stable (Fig. 1; Table 1). There are only two exceptions. The first one is the long-lived complex between $\mathrm{Cc}$ and CardioLipin (CL), a lipid allocated at the inner mitochondrial membrane (IMM). Such a complex triggers $\mathrm{CL}$ peroxidation and further $\mathrm{Cc}$ release at the beginning of apoptosis. The last step before $\mathrm{Cc}$ release is the highly dynamic interaction between $\mathrm{Cc}$ and $\mathrm{Bcl}-\mathrm{x} 2$ at the outer mitochondrial membrane (OMM). It is even more interesting that (1) all IMS-protein contacts performed by Cc show a high turnover and (2) that they are all involved in ET reactions-for instance, binding to bc $1, \mathrm{CcO}$, cytochrome b 5 ( $\mathrm{Cb} 5$ ), cytochrome c peroxidase (CcP), Erv1 and p66Shc. In 
contrast, the interactions of $\mathrm{Cc}$ at the cytosol-upon $\mathrm{Bcl}-\mathrm{x} 2$ and Apaf-1 binding-are not redox, regardless of whether they are stable or transient (Fig. 1; Table 1). Within such a frame, this review is focused on the complex regulatory network of transient intermolecular contacts hovering on $\mathrm{Cc}$, a moonlighting hemeprotein performing a high number of functions in the IMS and OMM (Fig. 2).

As for other proteins, the multitasks ascribed to $\mathrm{Cc}$ can be regulated by post-translational modifications and, in particular, by nitration or phosphorylation of tyrosine residues. Both modifications, mutually exclusive, can affect the way that $\mathrm{Cc}$ interacts with its physiological partners-either in mitochondria or in cytosol-but such effects are themselves highly dependent on which tyrosine is modified.

Nitration of $\mathrm{Cc}$ is caused by the excess of mitochondrial $\mathrm{R}(\mathrm{N}) \mathrm{OS}$, which can diffuse from extramitochondrial compartments into mitochondria or can be generated accidentally by the activity of the mitochondrial respiratory chain (Chance et al. 1979; Chen et al. 2003). Respiration is drastically impaired by nitration, no matter which tyrosine is nitrated (RodríguezRoldán et al. 2008). In contrast, only nitrated Tyr46, Tyr48 and Tyr74 block the apoptotic reaction (García-Heredia et al. 2010, unpublished data). Whereas Tyr48 and Tyr74 are highly conserved along evolution, Tyr46 is present in Cc from humans but not from other sources. An example of gain-of-function modification is the increase in peroxidase activity of Cc upon nitration (Cassina et al. 2000; Batthyány et al. 2005; García-Heredia et al. 2010), mainly of the nitrated Cc ( $n-C c)$ species that behave as high-spin proteins (Díaz-Moreno et al. 2011c).

Cytochrome c phosphorylation, whose specific phosphorylating kinase is still unknown, has been shown to inhibit ET between Cc and CcO (Lee et al. 2006; Yu et al. 2008). However, only phosphorylation of Cc-Tyr48 disrupts apoptosome activation (Pecina et al. 2010; GarcíaHeredia et al. 2011). Besides the tyrosines susceptible to phosphorylation, there are two other phosphorylation residues on human Cc, namely Thr28 and Ser47 (Zhao et al. 2011; Hüttemann et al. 2011a, b). Nevertheless, their functional consequences remain unknown.

\section{The role of $\mathrm{Cc}$ in mitochondrial respiration chain}

\section{The cytochrome bc 1 and cytochrome c complex}

The mitochondrial respiratory chain couples ET from reduction equivalents to molecular oxygen, with vectorial proton translocation across the lipid membrane. The generated electrochemical proton gradient drives ATP synthesis. Four multisubunit enzymes (complexes I-IV) are embedded in the IMM. The soluble protein Cc, located in the IMS, shuttles electrons between cytochrome bc 1 (complex III or ubiquinol/cytochrome c oxidoreductase) and CcO (complex IV) (Saraste 1999). These interactions are highly transient, enabling high turnover rates, which are essential for the continuous electron flow through the different components of the respiratory chain (Fig. 3).

Cytochrome bc 1 is a 500-kDa homodimeric multisubunit integral membrane protein complex. The catalytic core comprises cytochrome $b$, with two noncovalently attached heme groups; the so-called Rieske protein, with an iron-sulfur cluster; and cytochrome c 1 (Cc 1), with a covalently attached heme c group (Berry et al. 2000). The enzyme catalyzes the ET from 
ubiquinol to $\mathrm{Cc}$ coupled to the net translocation of protons over the mitochondrial membrane (Berry et al. 2000; Fig. 3).

The crystal structure of the mitochondrial bc 1-Cc complex reveals that there is a small nonpolar contact area (ca. 957 Á2), including a cation $-\pi$ interaction with the heme cofactors in the center surrounded by charged residues whose contribution to the interaction is mainly electrostatic (Lange and Hunte 2002). This is consistent with the two-step model of ET complex formation, in which the final complex first entails a primary unspecific recognition via electrostatic steering as an encounter that can be transiently stabilized to yield a productive and specific complex as an outcome. On one hand, the electrostatic component between Cc 1 and $\mathrm{Cc}$ accelerates protein association by limiting diffusion space, despite keeping the pairs of complementary charged residues far enough to avoid forming salt bridges. On the other, hydrophobic and cation- $\pi$ contact pairs define an area around the core of the bc $1-C c$ interface defined by the heme cleft with their pyrrole $C$ rings pointing toward each other, which allows ET to occur directly from c 1 heme to Cc heme (Lange and Hunte 2002). This has also been inferred not only from the orientation and close proximity of the heme groups in the bc 1-Cc crystallographic structure, but also from the estimated ET rates (Saraste 1999) and stopped-flow measurements revised by Yu et al. (2002). Such ET rates perfectly match those calculated by laser flash photolysis using ruthenium-labeled Cc derivatives (Tian et al. 2000; Engstrom et al. 2003). The rates are ionic strength-dependent. The first-order rate constant does not change as the ionic strength increases from 10 to $50 \mathrm{mM}$, but diminishes significantly with increasing ionic strength. At high ionic strength, the rate constant becomes Cc 1 concentration-dependent, which is indicative of a second-order kinetics (Yu et al. 2002, for revision). Interestingly, the ET between Cc 1 and Cc is fully reversible, consistent with the fact that the reduction potentials of both cytochromes are nearly the same.

More recently, a higher resolution bc 1-Cc structure was resolved, showing a substantially hydrated interface in which the relatively low surface complementary between the two hemeproteins provides space for hydration (Solmaz and Hunte 2008; Nyola and Hunte 2008). Interestingly, most of the water molecules are stabilized by interactions with $\mathrm{Cc} 1$ and not with Cc. The hydration pattern of Cc 1 rearranges significantly upon $C_{c}$ binding, resulting in a single water-molecule-mediated intermolecular hydrogen bond at the Cc 1-Cc interface (Solmaz and Hunte 2008). In contrast, comparable ET complexes such as CCP-CC show three interface water molecules that establish hydrogen bonds between both proteins (see below; Pelletier and Kraut 1992). The lack of salt bridges and hydrogen bonds, along with the high solvation of the interface, make the Cc 1-Cc interaction specifically transient and the lifetime of the complex relatively short. This correlates with the mobility mismatch of the positively charged interacting side chains of $\mathrm{Cc}$, which may further contribute to the undocking process (Solmaz and Hunte 2008).

Of interest is the 1:1 binding stoichiometry of bc 1-Cc complex. Cc binds specifically only to one of the two possible recognition sites of the dimeric bc 1 (Lange and Hunte 2002). This indicates that bc 1 might be able to reduce $\mathrm{Cc}$ with the second functional unit not being active, thereby supporting a sequential or independent mode. Recently, it has been demonstrated that electrons move freely within and between monomers of bc 1 , acting as a molecular-scale bus bar that increases the effective diffusion for Cc (Świerczek et al. 2010). 
Post-translational modifications of tyrosines from $\mathrm{Cc}$ can modulate the binding to $\mathrm{Cc} 1$. R(N)OS promotes tyrosine nitration of proteins, with $\mathrm{Cc}$ being the main target in mitochondria. The nitration of two out of five tyrosine residues - at positions 46 and 48-turns Cc into a high-spin species without significant changes in its secondary structure (Díaz-Moreno et al. 2011c), a finding that may explain the drop of ca. $100 \mathrm{mV}$ in the midpoint reduction potential value of $\mathrm{n}$ Cc forms (Rodríguez-Roldán et al. 2008). Thus, cellular respiration is partially disrupted by nitration because $\mathrm{Cc}$ is no longer isopotential with $\mathrm{Cc} 1$, and it becomes unable to accept electrons from the cytochrome bc 1 complex. Under (nitro)oxidative stress, the excess in $R(N) O S$ yielded from the first complexes of the respiratory chain could lead to a positive nitration-driven feedback cycle, with cytochrome bc 1 promoting the increase in $R(N) O S$ and $n-$ Cc levels.

On the other hand, phosphorylation of Cc-Tyr48 induces significant modifications in the heme environment without major structural change, namely an $80-\mathrm{mV}$ drop in the midpoint reduction potential value and inhibition of the electron flux between complexes III and IV (Yu et al. 2008; Pecina et al. 2010; García-Heredia et al. 2011).

\section{The cytochrome $\mathrm{c}$ and cytochrome $\mathrm{c}$ oxidase complex}

Cytochrome c oxidase is the last electron acceptor of the mitochondrial respiratory chain and catalyzes the reduction of molecular oxygen to water, coupling the free energy of water formation to proton translocation across the membrane (Papa et al. 2004; Fig. 3). Eukaryotic $\mathrm{CcO}$ contains 13 subunits, each different from the other, the catalytic core of the enzyme being formed by the three largest subunits: Cox1, Cox 2 and Cox3. Cox 1 contains one copper ion (termed CuB), whereas a binuclear copper binding site, named CuA, is located in Cox2 (Tsukihara et al. 1996). The delivery of copper to the CuA site during the process of mitochondrial CcO assembly is carried out by the Sco (Synthesis of cytochrome c oxidase) protein, which, in turn, receives copper from the chaperone Cox17 (Banci et al. 2011a). In eukaryotic organisms, in particular, the Sco protein develops additional functions to the $\mathrm{CcO}$ assembly, including mitochondrial signaling and regulation of copper homeostasis. Structural information for the eukaryotic $\mathrm{Cc}-\mathrm{CcO}$ complex has been recently reported (Sakamoto et al. 2011). One of the most interesting features is that the adduct is mainly stabilized by hydrophobic interactions between partners, which are mediated by the hydrophobic heme periphery and adjacent hydrophobic amino acid residues of $\mathrm{Cc}$. Such interactions place the two redox centers of $\mathrm{Cc}$ and $\mathrm{CcO}$ in close proximity.

In addition, charged residues near the hydrophobic core refine the orientation of $\mathrm{Cc}$ with respect to $\mathrm{CCO}$ in order to facilitate the strictly controlled ET reaction. Unexpectedly, negatively charged residues, along with Lys residues, are included in the interaction surface with the exception of Glu16 and Lys72 whose nuclear magnetic resonance (NMR) signals show no substantial perturbations although they surround the hydrophobic core and seem to be involved in the interaction with CcO (Roberts and Pique 1999).

The CUA site of CCO, which acts as an electron entry site (Yoshikawa et al. 1998), is surrounded by an exposed hydrophobic cluster containing aromatic residues-Trp104, Tyr105, Tyr121 and Phe206. The analysis of the intermolecular contacts found in Cc points out that the exposed hydrophobic $\mathrm{Cc}$ heme edge, as well as its adjacent hydrophobic residues, can interact with the 
hydrophobic cluster at the CUA site to form an ensemble that is competent for ET. Needless to say that the adducts among ET partners, as in the $\mathrm{Cc}-\mathrm{CcO}$ complex, are usually dynamic and transient to guarantee a high turnover (Prudêncio and Ubbink 2004). This dynamic model is compatible with the two-step docking mechanism, previously proposed for the Cc 1-Cc interaction. $\mathrm{Cc}$ and $\mathrm{CcO}$ are brought in close proximity and pre-oriented by long-range electrostatic forces responsible for the initial encounter complex in which different orientations have approximately the same energy. Hydrophobic interactions, acting at short distances, account for the formation of the more specific active complex upon rearrangement of the two partners (Prudêncio and Ubbink 2004).

In the prokaryotic counterpart between cytochrome c 552 (Cc 552) and the CuA subunit of CcO from Paracoccus denitrificants, hydrophobic contacts are limited to few residues from both proteins (Bertini et al. 2005), which can explain that the adduct remains in a highly dynamic ensemble of different orientations rather than in a productive single orientation. Interestingly, some of these conformations are active for ET, but others are not. The binding affinity of $\mathrm{CC}$ and $\mathrm{CcO}$ is essentially independent of the oxidation state of $\mathrm{Cc}$. However, modifications in the polarity of the $\mathrm{Cc}$ heme environment due to the relevant conformational change of Cc Lys13 towards its oxidized heme upon $\mathrm{CcO}$ binding decrease its affinity for $\mathrm{CcO}$ to be replaced later by the reduced Cc (Sakamoto et al. 2011).

Cc experiences multiple encounters with its two respiratory partners: bc 1 and CcO. However, only few of them are productive. The number of encounters, and hence the ET rate, may be increased by the formation of a bc 1-Cc-CcO supercomplex (Heinemeyer et al. 2007) and/or by increasing the concentration of the individual partners in the IMS. Nevertheless, recent cryoelectron tomography data on the respirasome-multisubunit supercomplex of the respiratory chain containing complexes I, III and IV-reveals that the Cc binding sites in bc 1 and $\mathrm{CcO}$ are placed further apart (Dudkina et al. 2011).

Tyrosine nitration significantly decreases the reactivity of $\mathrm{Cc}$ towards $\mathrm{CcO}$, impairs the respiratory ET process and enhances $\mathrm{R}(\mathrm{N}) \mathrm{OS}$ production by mitochondria (Rodríguez-Roldán et al. 2008). It is remarkable that the dependence of the ET rate constant upon CCO concentration reaches a saturation plateau with wild-type (WT) Cc, but linearly increases with $\mathrm{n}$-Cc. This suggests that the mechanism of $\mathrm{Cc}-\mathrm{CcO}$ binding includes the formation of a transient complex before ET, whereas the interaction between $\mathrm{n}-\mathrm{Cc}$ and $\mathrm{CcO}$ follows a collisional mechanism (Rodríguez-Roldán et al. 2008). The drastically diminished reactivity of Cc upon nitration is just contrary to what should be expected from the higher driving force of the reaction resulting from the lowering in reduction potential of $\mathrm{n}-\mathrm{Cc}$. However, such a decrease is a specific effect of nitration on the interaction with $\mathrm{CcO}$, since the effect on the reactivity of the $\mathrm{n}$-Cc toward other electron acceptors, such as flavins, is negligible (RodríguezRoldán et al. 2008). Cc tyrosine phosphorylation also leads to partial inhibition of the reaction with $\mathrm{CcO}$. While Tyr97-phosphorylated Cc yields sigmoidal kinetics of $\mathrm{CcO}$ reduction, hyperbolic responses are obtained with Tyr48-phosphorylated and WT Cc species (Lee et al. 2006; Yu et al. 2008). However, the highest turnover is reduced to half when Cc becomes phosphorylated at Tyr48 (Yu et al. 2008). 


\section{Cytochrome c acts as an electron shuttle between the outer and inner mitochondrial membranes: the cytochrome $b 5$ and cytochrome c complex}

Cytochrome $b 5$ is located at the inner surface of the OMM and transfers electrons from the cytosolic $\mathrm{NADH}$-using the mitochondrial outer membrane-bound form of $\mathrm{NADH}$-dependent cytochrome b 5 Reductase (Cb 5R) - to Cc in the IMS (Bernardi and Azzone 1981; Fig. 2). Thus, reduced $\mathrm{Cc}$ interferes with the respiratory chain, delivering electrons to $\mathrm{CcO}$, as corroborated by the complete inhibition of KCN-mediated CCO (Matlib and O'Brien 1976; Bernardi and Azzone 1981).

The demonstration that $\mathrm{Cc}$ communicates $\mathrm{OMM}$ and IMM implies that the oxidationreduction state of the cytosolic NADH system and mitochondrial oxidation-reduction reactions are closely dependent on each other.

The $\mathrm{Cb} 5-\mathrm{Cc}$ docking reveals an ensemble of orientations assumed by the hemeproteins rather than a single, well-defined conformation (Banci et al. 2003; Volkov et al. 2005; Deep et al. 2005). This is based on the magnitude of several NMR parameters, such as the chemical-shift perturbation for $\mathrm{Cb} 5$ and $\mathrm{Cc}$, which average to zero when proteins adopt a multitude of transient orientations within the complex. These orientations have nearly equal energies and are in fast exchange on the NMR time scale, thus resulting in an average of the chemical-shift perturbations over all orientations. In combination with the absence of close contacts and extensive desolvation, this explains the observed small chemical-shift perturbations due binding within the complex. In addition, the complex is electrostatically guided to guarantee the recognition and preorientation of the two proteins, as inferred from site-directed mutagenesis studies (Sun et al. 1999, 2001) and ionic strength titrations (Volkov et al. 2005). Whereas $\mathrm{Cc}$ uses a single surface formed by the positively charged lysine residues surrounding the heme crevice for interaction (Fig. 1), Cb 5 mainly requires its negatively charged region around the solvent-exposed heme edge.

Controversial data regarding the stoichiometry for this complex vary depending on the source of $\mathrm{Cc}$. In the complex between yeast $\mathrm{Cc}$ and bovine $\mathrm{Cb} 5$, the concept of a ternary $\mathrm{Cb} 5-(\mathrm{Cc}) 2$ complex, with an stoichiometry of 2:1, is supported by the two $\mathrm{Cb} 5$ surfaces involved in the interaction (Banci et al. 2003; Volkov et al. 2005). In one area Cc binds to the front side of $\mathrm{Cb} 5$ ("head-on" orientation), in the other Cc interacts at the left side of $\mathrm{Cb} 5$ ("side-on" orientation). Both docking solutions satisfy all experimental restraints in accordance with the dynamic nature of the complex. Among these adducts, only a few of them are ET active, even though they are not the most favorable for binding. In fact, the docked structures with the "head-on" orientation might represent ET-productive complexes, since this is the conformation in which the heme-to-heme distance is optimum for ET.

In contrast, those $\mathrm{Cb} 5-\mathrm{Cc}$ complexes formed by horse $\mathrm{Cc}$ occur in 1:1 stoichiometry and predominantly exist in a favored orientation (Shao et al. 2003; Deep et al. 2005). It is worth mentioning that the binding surface used by $\mathrm{Cc}$ to interact with $\mathrm{Cb} 5$ is independent of the source where it comes from (Deep et al. 2005).

The driving force for the $\mathrm{Cb} 5-\mathrm{CC}$ ET reaction may be significantly blocked upon nitration or phosphorylation of $\mathrm{Cc}$ as they both make the reduction potential drop. However, some 
additional factors, such as conformational fluctuations, have to be taken into account because they can limit the reaction rate, as demonstrated for the zinc-substituted $\mathrm{Cb} 5-\mathrm{Cc}$ complex (Durham et al. 1995).

\section{The role of $\mathrm{Cc}$ in $\mathrm{R}(\mathrm{N}) \mathrm{OS}$ metabolism}

\section{The R(N)OS-scavenging system: cytochrome c-cytochrome c peroxidase}

Cytochrome c peroxidase is an in vivo antioxidant that catalyzes the reduction of hydrogen peroxidase to water in the IMS (Yonetani and Ohnishi 1966), especially during the oxidative stress signaling (Fig. 3). Actually, CCP takes part in a complex cellular defense network against R(N)OS in eukaryotes (Giles et al. 2005; Jiang and English 2006; Scorolli et al. 2007).

Cytochrome c peroxidase, the first heme enzyme for which the crystal structure was solved (Poulos et al. 1980), is a highly $\alpha$-helical molecule organized in two domains. The heme cofactor occupies a hydrophobic crevice between both domains, with only one solventexposed pyrrole ring. Interestingly, the heme group is exclusively coordinated by a histidine, which acts as the only axial ligand. The sixth coordination position remains vacant and available for peroxide binding.

In the $\mathrm{Cc}-\mathrm{CcP}$ complex formation, there is a binding preference for the physiological partners from the same species, indicating a co-evolution of Cc and CCP. Electrostatics play a predominant role in the $\mathrm{Cc}-\mathrm{CcP}$ interaction, which, in turn, is independent of the $\mathrm{Cc}$ redox state. However, in the crystallographic structure of $\mathrm{Cc}-\mathrm{CcP}$, the interface is mainly maintained by multiple van der Waals contacts and a single intermolecular hydrogen bond (Pelletier and Kraut 1992). The small binding interface is formed by residues surrounding the Cc heme group located at a surface patch of CCP. The binding site pivots on a hot spot formed by two residues: Arg13 from Cc and Tyr39 from CCP, which are close enough to establish an intermolecular contact (Volkov et al. 2009).

As for the $\mathrm{Cb} 5-\mathrm{Cc}$ complex, the stoichiometry of $\mathrm{Cc}-\mathrm{CcP}$ has been a subject of debate. Not only the crystal but also the solution structure of $\mathrm{Cc}-\mathrm{CcP}$, as well as recent mutagenesis and cross-linking works (Pearl et al. 2007, 2008), support a single 1:1 binding ratio (Pelletier and Kraut 1992; Volkov et al. 2006). However, several studies propose that the interaction occurs with a 2:1 stoichiometry at low ionic strength, involving non-overlapping binding domains in which the second Cc molecule interacts with CCP in a weaker way (Zhou and Hoffmann 1993, 1994).

Binary complexes better agree with the possibility that $\mathrm{Cc}$ explores the $\mathrm{CcP}$ surface so as to yield an ample set of sub-populations that differ in their binding geometries. Actually, the Xray structure only represents the productive $\mathrm{Cc}-\mathrm{CcP}$ complex in a two-step binding mode, which corresponds to the high-affinity binding site and the ET-active conformation. Cc lies on this CcP-related orientation ca. 70\% of the lifetime of the complex (Volkov et al. 2006; Bashir et al. 2010). Cc spends the remaining time sampling multiple binding geometries in the dynamic encounter complex, as inferred from paramagnetic relaxation enhancement (PRE) NMR spectroscopy. The balance between the encounter complex and the productive complex is functionally relevant (Volkov et al. 2010). The encounter ensemble driven by electrostatic 
forces enhances the association rate and maybe accelerates the search of the optimal binding geometry. However, it exhibits low ET activity because of the large distance between redox centers. In contrast, the productive complex is ET-active, yet it must be somewhat unstable to guarantee a fast turnover (Volkov et al. 2010).

Ferric CcP is first oxidized by $\mathrm{H} 2 \mathrm{O} 2$ to compound $\mathrm{I}$, which is characterized by the presence of a oxyferryl (FelV) heme and an indolyl radical cation on Trp191 (Millett et al. 1995; Pettigrew et al. 1999). Afterward two molecules of ferrous Cc transfer one electron to both radical CcP sites, returning $\mathrm{CCP}$ to the native Felll state. However, there are some controversies about how the two electrons are transferred from two Cc molecules to CCP (Fig. 3). In this way, a second site for Cc binding to CcP has been described (Stemp and Hoffman 1993; Leesch et al. 2000). The first site includes the surface area solved by X-ray structure (Pelletier and Kraut 1992), so that the ET pathway requires a through-space electron jump from Cc heme to Ala193 of CcP, followed by through-bond travel with a special emphasis of Trp191 (Millett et al. 1995; Wang et al. 1996a; Pearl et al. 2008).

The indolyl radical cation on Trp191 is finally reduced by a second ferrous Cc molecule (Wang et al. 1996b), which transfers another electron to oxy-ferryl heme, returning CcP to its original state (Mei et al. 2002). Whether the latter Cc molecule binds to a low-affinity second site on CcP (Leesch et al. 2000; Mei et al. 2002) or both Cc molecules sequentially interact with the high-affinity site of $\mathrm{CCP}$ is still debated. However, recent studies almost exclude the ET function for the low-affinity site, at least at physiological ionic strength (Pearl et al. 2007; 2008).

Besides serving as a $\mathrm{R}(\mathrm{N}) \mathrm{OS}$ scavenger, the $\mathrm{Cc}-\mathrm{CcP}$ complex is coupled to the ET flow between Erv1-a flavin-dependent sulfhydryl oxidase-and Cc (Dabir et al. 2007; Figs. 2, 3). Actually, both $\mathrm{Cc}$ and $\mathrm{CCP}$ efficiently function to deliver electrons as Erv1-dependent redox acceptors. Erv1 forms a 1:1 complex with Cc stabilized by electrostatic forces, but does not apparently make direct contact with CCP (Fig. 3).

The Erv1-Cc ET reaction is thermodynamically favorable because of differences in the reduction potentials of both proteins, although $\mathrm{Cc}$ reduction is a one-electron reaction and Erv1 oxidation is a two-electron reaction (Dabir et al. 2007). Reduced Cc can further be reoxidized throughout a variety of pathways, including $\mathrm{CcO}$ from the respiratory chain (Bihlmaier et al. 2007) and CCP, at least in fungi (Dabir et al. 2007), as shown in Fig. 3.

On the other hand, Erv1 can be re-oxidized by direct reaction with molecular oxygen (Bihlmaier et al. 2007; Dabir et al. 2007; Riemer et al. 2011), resulting in the transfer of two electrons and the subsequent release of $\mathrm{R}(\mathrm{N}) \mathrm{OS}$ production, mainly hydrogen peroxidase, as described for p66Shc (see below). Thus, CcP can catalyze the reduction of peroxides to mitigate the (nitro)oxidative stress (Volkov et al. 2011, Fig. 3).

Post-translational changes of Cc may drastically alter in vivo the ET reactions from Erv1 to Cc and from $\mathrm{Cc}$ to $\mathrm{CcP}$ despite the 100-mV drop of the reduction potential of both $\mathrm{n}-\mathrm{Cc}$ and $\mathrm{p}-\mathrm{Cc}$ species, which still leaves a sizable positive driving force for ET from Erv1 to Cc and keeps the up-hill of ET between CC and CCP. Therefore, further studies are required to study the functional consequences of $\mathrm{Cc}$ modifications. 


\section{p66Shc triggers the $\mathrm{R}(\mathrm{N})$ OS production by oxidizing $\mathrm{Cc}$}

The respiratory chain can generate R(N)OS not only accidently by blocking the electron flux, but also through a specific enzymatic system that involves the p66Shc and Cc proteins (Fig. 3).

p66Shc is an adaptor protein of the Src homology family that contains two characteristic domains of the Src proteins (PTB, phosphotyrosine binding; and SH2, Src homology), and two extra domains enriched in prolines and glycines $(\mathrm{CH} 2$ and $\mathrm{CH} 1$, collagen homologous) that are abundant in collagen (Pelicci et al. 1992; Migliaccio et al. 1997; Pellegrini et al. 2005). This family is formed by two other proteins, p52Shc and p46Shc, which work as signal transducers of kinases (Pelicci et al. 1992; Migliaccio et al. 1997). A particular feature of this family is that the three proteins are coded by the same gene, with the same frame, so the only difference among them is the $\mathrm{N}$-terminal sequence, which is expanded from p46Shc (the shortest) to p66Shc (the longest) and which is responsible for both their localization and function. Both p52Shc and p46Shc act as adaptor proteins coupling the activation of the EGFR receptor to Ras and MAP kinase cascade. However, p66Shc behaves as an oxidoreductase that generates mitochondrial R(N)OS as signaling molecules for p53-induced apoptosis (Migliaccio et al. 1997; Trinei et al. 2002). In addition, p46Shc is exclusively located in mitochondria, whereas p52Shc and p66Shc are ubiquitous in cells (Ventura et al. 2004).

Under (nitro)oxidative stimuli, protein kinase $C \beta(P K C \beta$ ) carries out the phosphorylation of p66Shc at the level of a serine (Ser36) located at the $\mathrm{CH} 2$ domain (Migliaccio et al. 1999; Pinton et al. 2007). Phosphorylated p66Shc is, thus, substrate for the prolyl isomerase Pin-1, which recognizes and induces cis-trans isomerization of pSer-Pro bonds, triggering mitochondrial accumulation of phosphorylated p66Shc (Pinton et al. 2007).

In mitochondria, p66Shc is maintained in inactive state as part of a molecular complex, which includes the TIM-TOM import complex and Hsp70 (Orsini et al. 2004). After proapoptotic signaling, p66Shc is released in the IMS to oxidize Cc and catalyzes the production of hydrogen peroxide, increasing the R(N)OS levels (Giorgio et al. 2005). This leads to the collapse of the mitochondrial transmembrane potential as the result of the $\mathrm{R}(\mathrm{N}) \mathrm{OS}$-dependent opening of the transmembrane pore (Fig. 3). The role of p66Shc in keeping mitochondrial integrity correlates indeed with the expression levels of some $\mathrm{Bcl}-2$ family members, namely reduction of $\mathrm{Bcl}-\mathrm{xL}$ and $\mathrm{Bcl}-2$ and increase in Bax and Bak.

p66Shc uses a 52-amino acid sequence between the $\mathrm{CH} 2$ and PTB domains to transiently interact with $\mathrm{Cc}$. Such a sequence-the so-called cytochrome binding (CB) domain-contains a stretch of three consecutive residues (Glu132-Glu133-Trp134) that are essential for the interactions and ET reactions of Cc with CCO and CCP (Bertini et al. 2005; Pelletier and Kraut 1992; Volkov et al. 2006). Site-directed mutagenesis of p66Shc replacing both Glu132 and Glu133 by gutamine residues or Trp134 by phenylalanine abolishes the ET towards the hemeprotein, suggesting that the Glu132-Glu133-Trp134 stretch of p66Shc forms the Cc binding surface. The relevance of p66Shc-Cc interaction is demonstrated in cells either transfected with the p66Shc E132QE133Q mutant or devoid of WT p66Shc; both exhibit an extended lifespan and enhanced resistance against oxidative stress and apoptosis (Giorgio et al. 2005). 
Although CB-p66Shc is essential for binding to $\mathrm{Cc}, \mathrm{CH} 2$-p66Shc also contributes to complex formation, as proposed by Giorgio et al. (2005). This may explain why p52Shc, which lacks $\mathrm{CH} 2$, does weakly recognize Cc. Recently, p66Shc has been used as a platform in which not only Cc, but also protein kinase $C \delta(P K C \delta)$ bound to retinol lies to settle a functional quaternary complex for the activation of the PKC $\delta$ signalosome (Acin-Perez et al. 2010).

p66Shc is an atypical signal transducer that converts p53-dependent pro-apoptotic stimuli into redox signals by oxidizing $\mathrm{Cc}$. Therefore, p66Shc and $\mathrm{Cc}$ are proteins that control oxidative stress, cell fate and lifespan in mammals. The $\mathrm{Cc}-\mathrm{p} 66 \mathrm{Sh}$ c reaction is fed if an excess of reduced $\mathrm{Cc}_{\mathrm{C}}$ is present at a concentration comparable to p66Shc (Fig. 3). An increase in reduced Cc in the IMS takes place when $\mathrm{CcO}$ activity decreases, but also by redox signaling from Sco protein (Banci et al. 2011a), the membrane Cb 5R complex (Matlib and O'Brien 1976; Bernardi and Azzone 1981) and/or Erv1 (Dabir et al. 2007).

It remains to be determined how post-translational modifications of Cc tyrosines-either by nitration or by phosphorylation-affect $R(N) O S$ generation under stressed conditions through the p66Shc pathway. Within this frame, it is tempting to speculate that both $\mathrm{p}-\mathrm{Cc}$ and $\mathrm{n}-\mathrm{Cc}$ may be more efficient in reducing p66Shc since its reduction potential substantially drops compared to WT Cc (Pecina et al. 2010; García-Heredia et al. 2011). Moreover, the p66Shc/pCc interaction might be assisted by the p66Shc PTB domain, which specifically recognizes phosphotyrosine residues.

\section{The role of Cc in early apoptosis inside the mitochondria}

\section{Cc-mediated peroxidation of cardiolipin}

There are two different populations of Cc inside the IMS. Most of Cc is free or weakly membrane-bound through electrostatic interactions with the negatively charged phospholipid head groups (Mustonen et al. 1987; Demel et al. 1989; Stepanov et al. 2009). In addition, 15\% of $\mathrm{Cc}$ is tightly bound to the IMM not only by electrostatic interactions, but also by hydrophobic forces (Rytömaa et al. 1992).

Interestingly, the two Cc populations substantially differ in their functions. Free $\mathrm{Cc}$ or that transiently interacting with the membrane is involved in the ET between membrane complexes III and IV during oxidative phosphorylation, as previously described. It can also scavenge $\mathrm{R}(\mathrm{N}) \mathrm{OS}$ under homeostatic conditions (Pereverzev et al. 2003) or even promote R(N)OS formation via p66Shc (Pelicci et al. 1992). In contrast, tightly membrane-bound Cc triggers peroxidation of mitochondrial lipid membranes-and, in particular, of $\mathrm{CL}$-during nitrooxidative stress at the earlier steps of apoptosis (Kagan et al. 2004; Belikova et al. 2006; Fig. 3). CL represents ca. $25 \%$ of total mitochondrial lipids (Vik et al. 1981) and is the only known dimeric phospholipid that consists of two molecules of phosphatidylglycerol connected by a glycerol backbone. In homeostatic mitochondria, $\mathrm{CL}$ is predominantly located at the inner leaflet of the IMM (Daum 1985), being associated with complexes III and IV, among others (Fry and Green 1981; Eble et al. 1990; Robinson 1993; Gomez and Robinson 1999). Such interactions with $\mathrm{CL}$ make these complexes retain their functionality, like the CL-complex IV ensemble, which allows proton pumping during oxidative phosphorylation (Haines and Dencher 2002). In apoptotic cells there is a membrane translocation of almost $40 \%$ of $\mathrm{CL}$ from 
the inner to the outer leaflet of the IMM (Kagan et al. 2006). Then, less than $5 \%$ of total mitochondrial CL becomes accessible to interact with Cc (Cortese et al. 1995; Ott et al. 2002; Bayir et al. 2006).

Cytochrome $\mathrm{c}$ is bound to $\mathrm{CL}$ via two distinct sites, named A-site and C-site. A-site is involved in electrostatic interactions with the negatively charged head groups of $\mathrm{CL}$, whereas $\mathrm{C}$-site utilizes hydrophobic interactions with the fatty acyl chains of CL (Rytömaa et al. 1992). Therefore, the binding of $\mathrm{CL}$ to the $\mathrm{A}$-site of $\mathrm{Cc}$ is reversible and easily disrupted by increasing ionic strength. Actually, $\mathrm{Cc}$ is transiently in contact with the membrane through its lysines at positions 72,73 and 86 (Bayir et al. 2006; Sinibaldi et al. 2008; Fig. 1). In contrast, the C-site of Cc forms a tight and stable complex with $\mathrm{CL}$, with Asn52 playing a key role at the interface (Sinibaldi et al. 2008). Upon C-site binding, there are substantial conformational changes within Cc that alter the heme environment and the axial coordination of iron because of the insertion of one $\mathrm{CL}$ acyl chain into the hydrophobic groove of $\mathrm{Cc}$ while the other $\mathrm{CL}$ chains remain embedded within the IMM (Tuominen et al. 2002; Kalanxhi and Wallace 2007). More recently it has been suggested that two fatty acyls of CL may bind to Cc (Sinibaldi et al. 2010). Both scenarios essentially tether $\mathrm{Cc}$ to the membrane, lead to partial hemeprotein unfolding and turn the heme iron state to high-spin after disrupting the Fe-S $\delta$ (Met80) bond (Kagan et al. 2004). These changes let $\mathrm{H} 2 \mathrm{O} 2$ access the heme crevice of $\mathrm{Cc}$, which then behaves as a peroxidase enzyme (Kagan et al. 2004; Belikova et al. 2006).

Cytochrome c-catalyzed $\mathrm{CL}$ peroxidation is preceded by the formation of highly reactive intermediates containing tyrosyl radicals (Chen et al. 2004; Kagan et al. 2006). In the presence of oxidizable $\mathrm{CL}$, the tyrosyl radical can take a hydrogen atom from one of the $\mathrm{CL}$ acyl chains and yield a lipid radical that is further oxidized, finally yielding a $\mathrm{CL}$ hydroperoxide (Kagan et al. 2004; Bayir et al. 2006; Belikova et al. 2006; Kagan et al. 2006). Under pro-apoptotic conditions, the generation and accumulation of $\mathrm{R}(\mathrm{N}) \mathrm{OS}$ - and, in particular, of $\mathrm{H2O2}$ - by increased respiration rates promote $\mathrm{CL}$ peroxidation, as well as formation of the mitochondrial permeability transition pore (Fig. 3). Both events are key for the release of pro-apoptotic proteins from mitochondria to cytoplasm so as to trigger programmed cell death (PCD) (Kagan et al. 2006; Schug and Gottlieb 2009). Cc is one of those apoptotic factors required to form a functional apoptosome and further downstream caspase activation. The low affinity between $\mathrm{Cc}$ and $\mathrm{CL}$ upon peroxidation favors re-installation of the free soluble $\mathrm{Cc}$ pool inside the IMS, thus allowing further release of Cc (Shidoji et al. 1999). In addition, plant Cc 1, which suffers a caspase 3-dependent cleavage inside the IMS during apoptosis, seems to be also involved in Cc release into cytosol (Zhu et al. 2011). Moreover, plant Cc 1 is a protein with dual targeting, being localized in both mitochondrial and chloroplast organelles (Rödiger et al. 2011). Thus, it is tempting to speculate that Cc 1 plays a key role in the mechanism of transferring biosynthesis pathways across organelle borders. Activation of peroxidases that function via a heme group, such as Cc, typically requires the formation of a protein-bound radical; in the case of $\mathrm{Cc}$, a tyrosine radical has been identified. Site-directed mutagenesis of $\mathrm{Cc}$ tyrosines reveals that Tyr67-the tyrosine residue nearest the heme group-is the major contributor to the peroxidase activity of the Cc-CL complex (Kapralov et al. 2011). Questions arise whether peroxidation of mitochondrial lipid membranes-and, in particular, of $\mathrm{CL}$-may be efficiently triggered by post-translational modifications-nitration or phosphorylation-of $\mathrm{Cc}$ tyrosine residues. Actually, $\mathrm{n}-\mathrm{Cc}$, whose peroxidatic activity is substantially higher compared to WT Cc, 
is preferably associated to the IMM (García-Heredia et al. 2010; Oursler et al. 2005). Specific nitration of Tyr46 and/or Tyr48 of Cc residues turns its heme iron state into high-spin (DíazMoreno et al. 2011c) and allows the $\mathrm{CL}$ acyl chain to be more easily allocated between the hydrophobic Cc stretches (Kalanxhi and Wallace 2007; Sinibaldi et al. 2010). In addition, the tyrosine phosphorylation of $\mathrm{Cc}$ demonstrated by Hüttemann and co-workers may also tune the affinity of Cc towards CL (Lee et al. 2006; Yu et al. 2008). Tyr48-phosphorylated Cc behaves as an anti-apoptotic switch that fails in CL binding and CL peroxidation (Pecina et al. 2010; GarcíaHeredia et al. 2011). Since nitration and phosphorylation of the same tyrosine residue are mutually exclusive (Kong et al. 1996) (anti-apoptotic) Tyr48 phosphorylation could impair nitration of the same residue and prevent $\mathrm{Cc}$ from yielding any peroxidase activity under homeostatic conditions, whereas (pro-apoptotic) Tyr48 nitration could act as a mechanism to trigger early apoptosis after nitroxidative stress. Therefore, Cc signaling by post-translational control may regulate the early steps of PCD in mitochondria.

\section{Inhibition of Cc translocation to the cytosol by pro-survival Bcl-xL protein}

The anti-apoptotic role of $\mathrm{Bcl}-\mathrm{xL}$ can be explained by the formation of adducts with $\mathrm{Cc}$, which is sequestered in the cytosol, so that the apoptosome cannot be assembled (Fig. 3). The restricted motions of $\mathrm{Bcl}-\mathrm{xL}$ anchored to the OMM reduce the dimensionality of the recognition event between both proteins just at the entrance of $\mathrm{Cc}$ into the cytosolic space. As a consequence, a sensible increase in binding should efficiently take place in the cell with respect to the NMR data in vitro. Actually, the dissociation constant of the $\mathrm{Bcl}-\mathrm{xL} / \mathrm{Cc}$ interaction (in the order of $1 \mathrm{mM}$ ) determined by NMR indicates the formation of a transient, albeit specific, complex driven by the electrostatic term (Bertini et al. 2011a). Residues of CC optimizing intermolecular contacts with Bcl-xL differ from those forming ET adducts (Fig. 1). Certainly, the $\mathrm{Bcl}-\mathrm{xL} / \mathrm{Cc}$ binding does not require any ET and does not involve the participation of the Cc heme edge (Bertini et al. 2011a).

\section{Other physiological complexes of $\mathrm{Cc}$ in bacteria and plants}

\section{The cytochrome c and Sco complex}

Recently, Sco has been identified as a protein that interferes with the respiratory chain not only delivering copper to $\mathrm{CcO}$, but also reducing $\mathrm{Cc}$ in the periplasm of Pseudomonas putida (Banci et al. 2011a; Fig. 2). Sco would act as a redox sensor perceiving changes in the periplasmic reduction potential whose transmission to the cytoplasm for activating signaling pathways and cellular responses is crucial. Even though the multiple sequence alignment using several eukaryotic and prokaryotic Sco proteins yields a low global similarity, the CXXXC motif responsible for $\mathrm{Cc}$ reduction is well conserved, suggesting that the ET towards $\mathrm{Cc}$ may be an evolutionarily conserved function among species (Fig. 3). The driving force of Sco-Cc ET reaction may be impaired in $\mathrm{n}-\mathrm{Cc}$ and phosphorylated $\mathrm{Cc}(\mathrm{p}-\mathrm{Cc})$ forms, which show lower reduction potential values than WT Cc. However, the functional consequences of these posttranslational modifications remain unknown.

The cytochrome $c$ and GALDH complex 
Exclusively in plants, I-GAlactono-1,4-Lactone DeHydrogenase (GALDH) is another integral membrane-bound target of $\mathrm{Cc}$ from which electrons shuttle into the ET chain via $\mathrm{Cc}$ (Leferink et al. 2008). Recent data do suggest that GALDH catalyzes the l-ascorbate production with the concomitant reduction of Cc (Leferink et al. 2009). Neither the GALDH-CC complex structure nor the effects of post-translationally modified Cc have been elucidated yet.

\section{The non-physiological complexes of Cc}

Non-physiological complexes between redox proteins have also been studied. They exhibit fast ET and affinity constants, within the same range as the physiological partners (Fig. 1; Table 1). Among the non-physiological complexes of Cc reported in the literature, the one formed by adrenodoxin ( $\mathrm{Adx}$ ) and $\mathrm{Cc}$ has been widely analyzed because $\mathrm{Cc}$ serves as a model for cytochrome P450 (Fig. 2). Actually, Adx is involved in steroid hormone biosynthesis shuttling electrons between NADPH-dependent adrenodoxin reductase (AdR) and several cytochromes P450 inside the mitochondria (Fig. 3). As the one-electron transfer from (AdR) to Adx is the slowest, rate-limiting step (Lambeth and Kamin 1979), the fact that Adx and Cc show fast ET suggests that a complex is formed.

The $A d x-C c$ complex is entirely dynamic and can be considered as a pure encounter complex dominated by electrostatics - between four acidic patches in $\mathrm{Adx}$ and the positively charged area surrounding the heme group of $\mathrm{Cc}-$ and, nevertheless, active in ET (Worrall et al. 2003; $\mathrm{Xu}$ et al. 2008). The apparent lack of surface matching on both partners allows more than one orientation to be sampled (Fig. 1). Authors propose that these orientations most likely have similar energies and are in fast exchange in the NMR scale, thus resulting in averaging of several NMR parameters over all orientations. The absence of close contacts and extensive desolvation would explain the small signal perturbations upon complex formation, which suggests that the two metalloproteins sample other surfaces areas away from the predominant binding sites. Interestingly, the dipole moment of Adx does not seem to be involved in electrostatic steering among the proteins in the redox chain, including the nonphysiological target Cc, in contrast to what has been widely accepted (Hannemann et al. 2009).

\section{Mitochondrial scaffold of Cc: the homeostatic-to-apoptotic transition}

The mitochondrial signalosome of $\mathrm{Cc}$ is constituted by metabolic pathways that are closely linked to each other (Fig. 3).

Under homeostasis, Cc carries out the ET flux of the mitochondrial respiration in a controlled manner and ensures healthy mitochondrial membrane potentials. Eventually, R(N)OS can be accidentally generated by the own activity of the mitochondrial respiratory chain. Such radical species can efficiently be neutralized by enzymes like manganese superoxide dismutase or by the $\mathrm{Cc}-\mathrm{CCP}$ complex, which functions as a R(N)OS scavenger. Simultaneously, $\mathrm{Cc}$ can serve as the nexus between the cytosolic NADH-generating system and respiratory chain at the level of $\mathrm{CcO}$.

Indeed, the inactivation state of p66Shc is accompanied by the overexpression of $\mathrm{Bcl}-\mathrm{xL}$, which sequesters $\mathrm{Cc}$ from the cytosol to avoid PCD in the absence of stress. Under apoptotic conditions, $\mathrm{Cc}$ allows the respiration chain to work at the maximum rate up to yield an excess 
in $\mathrm{R}(\mathrm{N}) \mathrm{OS}$. This promotes oxidation and nitration of $\mathrm{Cc}$, which, in turn, might accelerate $\mathrm{R}(\mathrm{N}) \mathrm{OS}$ generation by transient ET to p66Shc, previously activated upon apoptosis. It is thus plausible to propose that the reduced $\mathrm{Cc}$ pool resulting from the $\mathrm{Cb} 5$, Erv1 and Sco pathways could also contribute to the increase in $\mathrm{R}(\mathrm{N}) \mathrm{OS}$ production, although the ET fluxes may be disrupted by post-translationally modified $\mathrm{Cc}$, while $\mathrm{CcP}$ is not efficient enough to neutralize extra R(N)OS. $\mathrm{R}(\mathrm{N}) \mathrm{OSs}$ are indeed responsible for hyperpolarization of the mitochondrial membranes by opening the transmembrane pore. At this stage, the peroxidation of $\mathrm{CL}$ catalyzed by $\mathrm{Cc}-$ especially the nitrated $\mathrm{Cc}$ species-is essential for the collapse of the mitochondrial membrane. Then, $\mathrm{Cc}$ is released into the cytosol where it stably assembles the apoptosome because of the lack of $\mathrm{Bcl}-\mathrm{xL}$ so as to amplify the PCD signal by activating the caspases cascade.

\section{Conclusions and outlook}

Puzzling the Cc-controlled complex network out in the cellular environment requires knowledge about contacts between partners and, eventually, the discovery of new targets. Figure 1 shows the $\mathrm{Cc}$ residues forming the interface with the $\mathrm{Cc}$ targets for which structural information is available. The interaction surface offered by $\mathrm{Cc}$ shifts from the area surrounding the heme crevice for those ET-active Cc complexes (Bertini et al. 2011b) to the opposite molecule side when the ET is not necessary. Therefore, the Cc mappings that comprise mitochondrial contacts are almost identical, since they include residues close to the heme edge. Still post-translational modifications, such as nitration and phosphorylation, of Cc need to be explored in the context of the hemeprotein and its interaction network with mitochondrial targets.

Because of the central role of $\mathrm{Cc}$ in lifespan regulation and cell fate by controlling both respiration and apoptosis, a deeper understanding of the signaling mechanisms involving $\mathrm{Cc}$, as well as their regulation by post-translational modifications of $\mathrm{Cc}$-phosphorylation and nitration-is essential. In addition, the identification of interfaces between $\mathrm{Cc}$ and its counterparts will enable the development and design of novel therapies. Other promising approaches are aimed at identifying drugs that inhibits the action of pro-survival-potential oncogenes-and pro-apoptotic-aging-related diseases-partners of Cc.

\section{Acknowledgments}

The authors wish to thank Jonathan Martínez-Fábregas for helpful advice and critical reading of the manuscript. This work was funded by the Spanish Ministry of Science and Innovation (BFU2009-07190) and the Andalusian Government (BIO198 and P08-CVI-3876). 


\section{References}

Acehan D, Jiang X, Morgan DG, Heuser JE, Wang X, Akey CW (2002) Three-dimensional structure of the apoptosome: implications for assembly, procaspase-9 binding, and activation. Mol Cell 9:423-432

Acin-Perez R, Hoyos B, Gong J, Vinogradov V, Fischman DA, Leitges M, Borhan B, Starkov A, Manfredi G, Hammerling $U$ (2010) Regulation of intermediary metabolism by the PKC $\delta$ signalosome in mitochondria. FASEB J 24:5033-5042

Banci I, Bertini I, Felli IC, Krippahl L, Kubicek K, Moura JJG, Rosato A (2003) A further investigation of the cytochrome b 5-cytochrome c complex. J Biol Inorg Chem 8:777-786

Banci L, Bertini I, Cavallaro G, Ciofi-Baffoni S (2011a) Seeking the determinants of the elusive functions of Sco proteins. FEBS J 278:2244-2262

Banci L, Bertini I, Ciofi-Baffoni S, Kozyreva T, Mori M, Wang S (2011b) Sco proteins are involved in electron transfer processes. J Biol Inorg Chem 16:391-403

Bashir Q, Volkov AN, Ullmann GM, Ubbink M (2010) Visualization of the encounter ensemble of the transient electron transfer complex of cytochrome $\mathrm{c}$ and cytochrome c peroxidase. J Am Chem Soc 132:241-247

Bashir Q, Scanu S, Ubbink M (2011) Dynamics in electron transfer protein complexes. FEBS J 278:1391-1400

Batthyány C, Souza JM, Durán R, Cassina A, Cerveñansky C, Radi R (2005) Time course and site(s) of cytochrome c tyrosine nitration by peroxynitrite. Biochemistry 44:8038-8046

Bayir H, Fadeel B, Palladino MJ, Witasp E, Kurnikov IV, Tyurina YY, Tyurin VA, Amoscato AA, Jiang J, Kochanek PM, DeKosky ST, Greenberger JS, Shvedova AA, Kagan VE (2006) Apoptotic interactions of cytochrome $c$ : redox flirting with anionic phospholipids within and outside of mitochondria. Biochim Biophys Acta 1757:648-659

Belikova NA, Vladimirov YA, Osipov AN, Kapralov AA, Tyurin VA, Potapovich MV, Basova LV, Peterson J, Kurnikov IV, Kagan VE (2006) Peroxidase activity and structural transitions of cytochrome $\mathrm{c}$ bound to cardiolipin-containing membranes. Biochemistry 45:4998-5009

Bernardi P, Azzone GF (1981) Cytochrome c as an electron shuttle between the outer and inner mitochondrial membrane. J Biol Chem 256:7187-7192

Berry EA, Guergova-Kuras M, Huang LS, Crofts AR (2000) Structure and function of cytochrome bc complexes. Annu Rev Biochem 69:1005-1075

Bertini I, Cavallaro G, Rosato R (2005) A structural model for the adduct between cytochrome c and cytochrome c oxidase. J Biol Inorg Chem 10:613-624

Bertini I, Chevance S, Del Conte R, Lalli D, Turano P (2011a) The anti-apoptotic Bcl-xL protein, a new piece in the puzzle of cytochrome $C$ interactome. PLos One. doi:10.1371/journal.pone.0018329 
Bertini I, Cavallaro G, Rosato A (2011b) Principles and patterns in the interaction between mono-heme cytochrome $\mathrm{c}$ and its partners in electron transfer processes. Metallomics. doi:10.1039/c0mt00108b

Bihlmaier K, Mesecke N, Terzyiska N, Bien M, Hell K, Herrmann JM (2007) The disulfide relay system of mitochondria is connected to the respiratory chain. J Cell Biol 179:389-395

Cai J, Yang J, Jones DP (1998) Mitochondrial control of apoptosis: the role of cytochrome c. Biochim Biophys Acta 1366:139-149

Cassina AM, Hodara R, Souza JM, Thomson L, Castro L, Ischiropoulos H, Freeman BA, Radi R (2000) Cytochrome c nitration by peroxynitrite. J Biol Chem 275:21409-21415

Chance B, Sies H, Boveris A (1979) Hydroperoxide metabolism in mammalian organs. Physiol Rev 59:527-605

Chen Q, Vazquez EJ, Moghaddas S, Hoppel CL, Lesnefsky EJ (2003) Production of reactive oxygen species by mitochondria: central role of complex III. J Biol Chem 278:36027-36031

Chen YR, Chen CL, Chen W, Zweier JL, Augusto O, Radi R, Mason RP (2004) Formation of protein tyrosine ortho-semiquinone radical and nitrotyrosine from cytochrome c-derived tyrosyl radical. J Biol Chem 279:18054-18062

Cortese J, Voglino AL, Hackenbrock CR (1995) Persistence of cytochrome c binding to membranes at physiological mitochondrial intermembrane space ionic strength. Biochim Biophys Acta 1228:216-228

Dabir DV, Leverich EP, Kim S-K, Tsai FD, Hirasawa M, Knaff DB, Koehler CM (2007) A role for cytochrome $c$ and cytochrome $c$ peroxidase in electron shuttling from Erv1. EMBO J 26:48014811

Daum G (1985) Lipids of mitochondria. Biochim Biophys Acta 822:1-42

Deep S, Im S-C, Zuiderweg ERP, Waskell L (2005) Characterization and calculation of a cytochrome c-cytochrome b 5 complex using NMR data. Biochemistry 44:10654-10668

Demel RA, Jordi W, Lambrechts H, van Damme H, Hovius R, de Kruijff B (1989) Differential interactions of apo- and holocytochrome $\mathrm{c}$ with acidic membrane lipids in model systems and the implications for their import into mitochondria. J Biol Chem 264:3988-3997

Díaz-Moreno I, De La Rosa MA (2011a) Transient interactions between biomolecules. Eur Biophys J. doi:10.1007/s00249-011-0728-x

Díaz-Moreno I, De La Rosa MA (2011b) Transient interactions in metalloproteins. FEBS J. doi:10.1111/j.1742-4658.2011.08065.x

Díaz-Moreno I, García-Heredia JM, Díaz-Quintana A, Teixeira M, De La Rosa MA (2011c) Nitration of tyrosines 46 and 48 induces the specific degradation of cytochrome $c$ upon change of the heme iron state to high-spin. Biochem Biophys Acta Bioenerg. doi:10.1016/j.bbabio.2011.09.012 
Dudkina NV, Kudryashev M, Stahlberg H, Boekema EJ (2011) Interaction of complexes I, III, and IV within the bovine respirasome by single particle cryoelectron tomography. Proc Natl Acad Sci USA 108:15196-15200

Durham B, Fairris JL, McLean M, Millett F, Scott JR, Sligar SG, Willie A (1995) Electron transfer from cytochrome b 5 to cytochrome c. J Bioenerg Biomembr 27:331-340

Eble KS, Coleman WB, Hantgan RR, Cunningham CC (1990) Tightly associated cardiolipin in the bovine heart mitochondrial ATP synthase as analyzed by 31P nuclear magnetic resonance spectroscopy. J Biol Chem 265:19434-19440

Engstrom G, Rajagukguk R, Saunders AJ, Patel CN, Rajagukguk S, Merbitz-Zahradnik T, Xiao K, Pielak GJ, Trumpower B, Yu C-A, Yu L, Durham B, Millet F (2003) Design of a ruthenium-labeled cytochrome $\mathrm{c}$ derivative to study electron transfer with the cytochrome bc 1 complex. Biochemistry 42:2816-2824

Fry M, Green DE (1981) Cardiolipin requirement for electron transfer in complex I and III of the mitochondrial respiratory chain. J Biol Chem 256:1874-1880

García-Heredia JM, Díaz-Moreno I, Nieto PM, Orzáez M, Kocanis S, Teixeira M, Pérez-Payá E, Díaz-Quintana A, De la Rosa MA (2010) Nitration of tyrosine 74 prevents human cytochrome c to play a key role in apoptosis signaling by blocking caspase- 9 activation. Biochem Biophys Acta Bioenerg 1797:981-993

García-Heredia JM, Díaz-Quintana A, Salzano M, Orzáez M, Pérez-Payá E, Teixeira M, De la Rosa MA, Díaz-Moreno I (2011) Tyrosine phosphorylation turns alkaline transition into a biologically relevant process and makes human cytochrome c behave as an anti-apoptotic switch. J Biol Inorg Chem. doi:10.1007/s00775-011-0804-9

Giles SS, Perfect JR, Cox GM (2005) Cytochrome c peroxidase contributes to the antioxidant defense of Cryptococcus neoformans. Fungal Genet Biol 42:20-29

Giorgio M, Migliaccio E, Orsini F, Paolucci D, Moroni M, Contursi C, Pelliccia G, Luzi L, Minucci S, Marcaccio M, Pinton P, Rizzuto R, Bernardi P, Paolucci F, Pelicci PG (2005) Electron transfer between cytochrome $\mathrm{c}$ and p66Shc generates reactive oxygen species that trigger mitochondrial apoptosis. Cell 122:221-233

Gomez B Jr, Robinson NC (1999) Phospholipase digestion of bound cardiolipin reversibly inactivates bovine cytochrome bc 1. Biochemistry 38:9031-9038

Haines TH, Dencher NA (2002) Cardiolipin: a proton trap for oxidative phosphorylation. FEBS Lett 528:35-39

Hannemann F, Guyot A, Zöllner A, Müller JJ, Heinemann U, Bernhardt R (2009) The dipole moment of the electron carrier adrenodoxin is not critical for redox partner interaction and electron transfer. J Inorg Biochem 103:997-1004

Heinemeyer J, Braun H-P, Boekema EJ, Kouřil R (2007) A structural model of the cytochrome c reductase/oxidase supercomplex from yeast mitochondria. J Biol Chem 282:12240-12248 
Hüttemann M, Pecina $P$, Rainbolt $M$, Sanderson TH, Kagan VE, Samavati L, Doan JW, Lee I (2011a) The multiple functions of cytochrome $c$ and their regulation in life and death decisions of the mammalian cell: from respiration to apoptosis. Mitochondrion 11:369-381

Hüttemann M, Helling S, Sanderson TH, Sinkler C, Samavati L, Mahapatra G, Varughese A, Lu G, Liu J, Ramzan R, Vogt S, Grossman LI, Doan JW, Marcus K, Lee I (2011b) Regulation of mitochondrial respiration and apoptosis through cell signaling: cytochrome $\mathrm{c}$ oxidase and cytochrome $\mathrm{c}$ in ischemia/reperfusion injury and inflammation. Biochim Biophys Acta. doi:10.1016/j.bbabio.2011.07.001

Jeng WY, Chen CY, Chang HC, Chuang WJ (2002) Expression and characterization of recombinant human cytochrome $\mathrm{c}$ in E. coli. J Bioenerg Biomembr 34:423-431

Jiang $H$, English AM (2006) Phenotypic analysis of the ccp1 $\Delta$ and $\operatorname{ccp} 1 \Delta$-ccp1 W191F mutant strains of Saccharomyces cerevisiae indicates that cytochrome c peroxidase functions in oxidative-stress signaling. J Inorg Biochem 100:1996-2008

Kagan VE, Borisenko GG, Tyurina YY, Tyurin VA, Jiang J, Potapovich Al, Kini V, Amoscato AA, Fujii Y (2004) Oxidative lipidomics of apoptosis: redox catalytic interactions of cytochrome $c$ with cardiolipin and phosphatidylserine. Free Rad Biol Med 37:1963-1985

Kagan VE, Tyurina YY, Batir H, Chu CT, Kapralov AA, Vlasova II, Belikova NA, Tyurin VA, Amoscato A, Epperly M, Greenberger J, DeKosky S, Shvedova AA, Jiang J (2006) The "proapoptotic genies" get out of mitochondria: oxidative lipidomics and redox activity of cytochrome c/cardiolipin complexes. Chem Biochem Interact 163:15-28

Kalanxhi E, Wallace CJ (2007) Cytochrome c impaled: investigation of the extended lipid anchorage of a soluble protein to mitochondrial membrane models. Biochem J 407:179-187

Kapralov AA, Yanamala N, Tyurina YY, Castro L, Samhan-Arias AK, Vladimirov YA, Maeda A, Mylnikov D, Demicheli V, Tortora V, Klein-Seetharaman J, Radi R, Kagan VE (2011) Topography of tyrosine residues and their involvement in peroxidation of polyunsaturated cardiolipin in cytochrome c/cardiolipin peroxidase complexes. Biochim Biophys Acta 1808:2147-2155

Kong SK, Yim MB, Stadtman ER, Chock PB (1996) Peroxynitrite disables the tyrosine phosphorylation regulatory mechanism: lymphocyte-specific tyrosine kinase fails to phosphorylate nitrated cdc2(6-20)NH2 peptide. Proc Natl Acad Sci USA 93:33777-33782

Lambeth JD, Kamin H (1979) Adrenodoxin reductase: adrenodoxin complex flavin to iron-sulfur transfer as the rate-limiting step in the NADPH-cytochrome c reductase reaction. J Biol Chem 254:2766-2774

Lange C, Hunte C (2002) Crystal structure of the yeast cytochrome bc 1 complex with its bound substrate cytochrome c. Proc Natl Acad Sci USA 99:2800-2805

Lee I, Salomon AR, Yu K, Doan JW, Grossman LI, Hüttemann M (2006) New prospects for an old enzyme: mammalian cytochrome $c$ is tyrosine-phosphorylated in vivo. Biochemistry 47:91219128 
Leesch VW, Bujous J, Mauk AG, Hoffman BM (2000) Cytochrome c peroxidase-cytochrome c complex: locating the second binding domain on cytochrome c peroxidase with site-directed mutagenesis. Biochemistry 39:10132-10139

Leferink NGH, van der Berg WAM, van Berkel WJH (2008) I-Galactono- $\gamma$-lactone dehydrogenase from Arabidopsis thaliana, a flavoprotein involved in vitamin $\mathrm{C}$ biosynthesis. FEBS J 275:713-726

Leferink NGH, Fraaije MW, Joosten H-J, Schaap PJ, Mattevi A, van Berkel WJH (2009) Identification of a gatekeeper residue that prevents dehydrogenases from acting as oxidases. J Biol Chem 284:4392-4397

Louie GV, Brayer GD (1990) High-resolution refinement of yeast iso-1-cytochrome c and comparisons with other eukaryotic cytochromes c. J Mol Biol 214:527-555

Matlib MA, O'Brien PJ (1976) Properties of rat liver mitochondria with intermembrane cytochrome c. Arch Biochem Biophys 173:27-33

Mei H, Geren L, Miller MA, Durham B, Millett F (2002) Role of the low-affinity binding site in electron transfer from cytochrome $c$ to cytochrome $c$ peroxidase. Biochemistry 41:3968-3976

Migliaccio E, Mele S, Salcini AE, Pelicci G, Lai K-MV, Superti-Furga G, Pawson T, Di Fiore PP, Lanfrancone L, Pelicci PG (1997) Opposite effects of the p52Shc/p46Shc and p66Shc splicing isoforms on the EGF receptor-MAP kinase-fos signalling pathway. EMBO J 16:706-716

Migliaccio E, Giorgio M, Mele S, Pelicci G, Reboldi P, Pandolfi PP, Lanfrancone L, Pelicci PG (1999) The p66Shc adaptor protein controls oxidative stress response and life span in mammals. Nature 402:309-313

Millett F, Miller MA, Geren L, Durham B (1995) Electron transfer between cytochrome $c$ and cytochrome c peroxidase. J Bioenerg Biomembr 27:341-351

Moore GR, Pettigrew GW (1990) Cytochromes c. Evolutionary, structural, and physicochemical aspects. Springer, New York

Mustonen P, Virtanen JA, Somerharju PJ, Kinnunen PKJ (1987) Binding of cytochrome c to liposomes as revealed by the quenching of fluorescence from pyrene-labeled phospholipids. Biochemistry 26:2991-2997

Nyola A, Hunte C (2008) A structural analysis of the transient interaction between the cytochrome bc 1 complex and its substrate cytochrome c. Biochem Soc Trans 36:981-985

Orrenius S (2007) Reactive oxygen species in mitochondria-mediated cell death. Drugs Metab Res 39:443-455

Orsini F, Migliaccio E, Moroni M, Contursi C, Raker VA, Piccini D, Martin-Padura I, Pelliccia G, Trinei M, Bono M, Puri C, Tacchetti C, Ferrini M, Mannucci R, Nicoletti I, Lanfrancone L, Giorgio M, Pelicci PG (2004) The life span determinant p66Shc localizes to mitochondria where it associates with mitochondrial heat shock protein 70 and regulates trans-membrane potential. J Biol Chem 279:25689-25695 
Ott M, Robertson J, Gogvadze V, Zhivotovsky B, Orrenius S (2002) Cytochrome c release from mitochondria proceeds by a two-step process. Proc Natl Acad Sci USA 99:1259-1263

Oursler MJ, Bradley EW, Elfering SL, Giulivi C (2005) Native, not nitrated, cytochrome c and mitochondria-derived hydrogen peroxide drive osteoclast apoptosis. Am J Physiol Cell Physiol 288:156-168

Papa S, Capitanio N, Capitanio G (2004) A cooperative model for proton pumping in cytochrome c oxidase. Biochem Biophys Acta 1655:353-364

Pearl NM, Jacobson T, Arisa M, Vitello LB, Erman JE (2007) Effect of single-site charge-reversal mutations on the catalytic properties of yeast cytochrome $c$ peroxidase: mutations near the high-affinity cytochrome $c$ binding site. Biochemistry 46:8263-8272

Pearl NM, Jacobson T, Meyen C, Clementz AG, Ok EY, Choi E, Wilson K, Vitello LB, Erman JE (2008) Effect of single-site charge-reversal mutations on the catalytic properties of yeast cytochrome c peroxidase: evidence for a single, catalytically active, cytochrome c binding domain. Biochemistry 47:2766-2775

Pecina P, Borisenko GG, Belikova NA, Tyurina Y, Pecinova A, Lee I, Samhan-Arias AK, Przyklenk K, Kagan VE, Huttemann M (2010) Phosphomimetic substitution of cytochrome c tyrosine 48 decreases respiration and binding to cardiolipin and abolishes ability to trigger downstream caspase activation. Biochemistry 49:6705-6710

Pelicci G, Lanfrancone L, Grignani F, McGlade J, Cavallo F, Forni G, Nicoletti I, Grignani F, Pawson T, Pelicci PG (1992) A novel transforming protein (SHC) with an SH2 domain is implicated in mitogenic signal transduction. Cell 70:93-104

Pellegrini M, Pacini S, Baldari CT (2005) p66Shc: the apoptotic side of Shc proteins. Apoptosis 10:13-18

Pelletier H, Kraut J (1992) Crystal structure of a complex between electron transfer partners, cytochrome c peroxidase and cytochrome c. Science 258:1748-1755

Pereverzev MO, Vygodina TV, Konstantinov AA, Skulachev VP (2003) Cytochrome c, an ideal antioxidant. Biochem Soc Trans 31:1312-1315

Pettersen EF, Goddard TD, Huang CC, Couch GS, Greenblatt DM, Meng EC, Ferrin TE (2004) UCSF Chimera-a visualization system for exploratory research and analysis. J Comput Chem 25:1605-1612

Pettigrew GW, Prazeres S, Costa C, Palma N, Krippahl L, Moura I, Moura JJG (1999) The structure of an electron transfer complex containing a cytochrome $\mathrm{c}$ and a peroxidase. J Biol Chem 274:11383-11389

Pinton P, Rimessi A, Marchi S, Orsini F, Migliaccio E, Giorgio M, Contursi C, Minucci S, Mantovani F, Wieckowski MR, Del Sal G, Pelicci PG, Rizzuto R (2007) Protein kinase C $\beta$ and prolyl isomerase 1 regulate mitochondrial effects of the life-span determinant p66Shc. Science 315:659-663 
Poulos TL, Freer ST, Alden RA, Edwards SJ, Skoglands U, Takio K, Eriksson B, Xuong N-H, Yonetani T, Kraut J (1980) The crystal structure of cytochrome c peroxidase. J Biol Chem 255:575-580

Prudêncio M, Ubbink M (2004) Transient complexes of redox proteins: structural and dynamic details from NMR studies. J Mol Recognit 17:524-539

Reincke B, Perez C, Pristovsek P, Lucke C, Ludwig C, Lohr F, Rogov VV, Ludwig B, Ruterjans H (2001) Solution structure and dynamics of the functional domain of Paracoccus denitrificans cytochrome c(552) in both redox states. Biochemistry 40:12312-12320

Riemer J, Fischer M, Hermann JM (2011) Oxidation-driven protein import into mitochondria: insights and blind spots. Biochim Biophys Acta 1808:981-989

Roberts VA, Pique ME (1999) Definition of the interaction domain for cytochrome $c$ on cytochrome c oxidase. J Biol Chem 274:38051-38060

Robinson NC (1993) Functional binding of cardiolipin to cytochrome c oxidase. J Bioenerg Biomembr 25:153-163

Rödiger A, Baudisch B, Langner U, Klösgen RB (2011) Dual targeting of a mitochondrial protein: the case study of cytochrome $c 1$. Mol Plant 4:679-687

Rodríguez-Roldán V, García-Heredia JM, Navarro JA, De la Rosa MA, Hervás M (2008) Effect of nitration on the physicochemical and kinetic features of wild-type and mono-tyrosine mutants of human respiratory cytochrome c. Biochemistry 47:12371-12379

Rytömaa M, Mustonen P, Kinnunen PK (1992) Reversible, nonionic, and pH-dependent association of cytochrome $c$ with cardiolipin-phosphatidylcholine liposomes. J Biol Chem 267:22243-22248

Sakamoto K, Kamiya M, Imai M, Shinzawa-Itoh K, Uchida T, Kawano K, Yoshikawa S, Ishimori K (2011) NMR basis for interprotein electron transfer gating between cytochrome $c$ and cytochrome c oxidase. Proc Natl Acad Sci USA 108:12271-12276

Saraste M (1999) Oxidative phosphorylation at the fin de siecle. Science 283:1488-1493

Schug ZT, Gottlieb E (2009) Cardiolipin acts as a mitochondrial signaling platform to launch apoptosis. Biochim Biophys Acta 1788:2022-2031

Scorolli L, Meduri A, Morara M, Scalinci SZ, Meduri RA (2007) Effect of cytochrome c peroxidase on the corneal epithelial healing process after excimer laser photoablation in transgenic mice. Eur Surg Res 39:82-87

Shao W, Im S-C, Zuiderweg ERP, Waskell L (2003) Mapping the binding interface of the cytochrome b 5-cytochrome c complex by nuclear magnetic resonance. Biochemistry 42:14774-14784 
Shidoji Y, Hayashi K, Komura S, Ohishi N, Yagi K (1999) Loss of molecular interaction between cytochrome $\mathrm{c}$ and cardiolipin due to lipid peroxidation. Biochem Biophys Res Commun 264:343-347

Sinibaldi F, Fiorucci L, Patriarca A, Lauceri R, Ferri T, Coletta M, Santucci R (2008) Insights into cytochrome c-cardiolipin interaction. Role played by ionic strength. Biochemistry 47:69286935

Sinibaldi F, Howes BD, Piro MC, Polticelli F, Bombelli C, Ferri T, Coletta M, Smulevich G, Santucci R (2010) Extended cardiolipin anchorage to cytochrome c: a model for proteinmitochondrial membrane binding. J Biol Inorg Chem 15:689-700

Solmaz SRN, Hunte C (2008) Structure of complex III with bound cytochrome c in reduced state and definition of a minimal core interface for electron transfer. J Biol Chem 283:17542-17549

Stemp EDA, Hoffman BM (1993) Cytochrome c peroxidase binds two molecules of cytochrome c: evidence for a low-affinity, electron transfer-active site on cytochrome c peroxidase. Biochemistry 32:10848-10865

Stepanov G, Gnedenko O, Mol'nar A, Ivanov A, Vladimirov Y, Osipov A (2009) Evaluation of cytochrome $c$ affinity to anionic phospholipids by means of surface plasmon resonance. FEBS Lett 583:97-100

Sun Y-L, Wang Y-H, Yan M-M, Sun B-Y, Xie Y, Huang Z-X, Jiang S-K, Wu H-M (1999) Structure, interaction and electron transfer between cytochrome $b 5$, its E44A and/or E56A mutants and cytochrome c. J Mol Biol 285:347-359

Sun Y-L, Wang Y-H, Qian C, Lu J, Li E, Wang W, Lu J, Xie Y, Wang J, Zhu D, Huang Z-X, Tang W (2001) Solution structure of cytochrome b 5 mutant (E44/48/56A/D60A) and its interaction with cytochrome c. Eur J Biochem 268:1620-1630

Świerczek M, Cieluch E, Sarewicz M, Borek A, Moser CC, Dutton PL, Osyczka A (2010) An electronic bus bar lies in the core of cytochrome bc 1. Science 329:451-454

Tian H, Sadoski R, Zhang L, Yu C-A, Yu L, Durham B, Millet F (2000) Definition of the interaction domain for cytochrome $c$ on the cytochrome $b c(1)$ complex. Steady-state and rapid kinetic analysis of electron transfer between cytochrome $\mathrm{c}$ and Rhodobacter sphaeroides cytochrome bc(1) surface mutants. J Biol Chem 275:9587-9595

Trinei M, Giorgio M, Cicalese A, Barozzi S, Ventura A, Migliaccio E, Milia E, Martin Padura I, Raker VA, Maccarana M, Petronilli V, Minucci S, Bernardi P, Lanfrancone L, Pelicci PG (2002) A p53-p66Shc signalling pathway controls intracellular redox status, levels of oxidation-damaged DNA and oxidative stress-induced apoptosis. Oncogene 21:3872-3878

Tsukihara T, Aoyama H, Yamashita E, Tomizaki T, Yamaguchi H, Shinzawa-Itoh K, Nakashima R, Yaono R, Yoshikawa S (1996) The whole structure of the 13-subunit oxidized cytochrome c oxidase at 2.8 Á. Science 272:1136-1144 
Tuominen EKJ, Wallace CJA, Kinnunen PVJ (2002) Phospholipid-cytochrome c interaction: evidence for the extended lipid anchorage. J Biol Chem 277:8822-8826

Ubbink M (2009) The courtship of proteins: understanding the encounter complex. FEBS Lett 583:1060-1066

Ventura A, Maccarana M, Raker VA, Pelicci PG (2004) A cryptic targeting signal induces isoform-specific localization of p46Shc to mitochondria. J Biol Chem 279:2299-2306

Vik SB, Georgevich G, Capaldi RA (1981) Diphosphatidylglycerol is required for optimal activity of beef cytochrome c oxidase. Proc Natl Acad Sci USA 78:1456-1460

Volkov AN, Ferrari D, Worrall JAR, Bonvin AMJJ, Ubbink M (2005) The orientations of cytochrome $\mathrm{c}$ in the highly dynamic complex with cytochrome b 5 visualized by NMR and docking using HADDOCK. Prot Sci 14:799-811

Volkov AN, Worrall JAR, Holtzmann E, Ubbink M (2006) Solution structure and dynamics of the complex between cytochrome $\mathrm{c}$ and cytochrome c peroxidase determined by paramagnetic NMR. Proc Natl Acad Sci USA 103:18945-18950

Volkov AN, Bashir Q, Worrall JAR, Ubbink M (2009) Binding hot spot in the weak protein complex of physiological redox partners yeast cytochrome $\mathrm{c}$ and cytochrome $\mathrm{c}$ peroxidase. $\mathrm{J}$ Mol Biol 385:1003-1013

Volkov AN, Bashir Q, Worrall JAR, Ullmann GM, Ubbink M (2010) Shifting the equilibrium between the encounter state and the specific form of a protein complex by interfacial point mutations. J Am Chem Soc 132:11487-11495

Volkov AN, Nicholls P, Worrall JAR (2011) The complex of cytochrome c and cytochrome c peroxidase. The end of the road? Biochim Biophys Acta. doi:10.1016/j.bbabio.2011.07.010

Wang K, Mei H, Geren L, Miller MA, Saunders A, Wang X, Waldner JL, Pielak GJ, Durham B, Millett $F$ (1996a) Design of a ruthenium-cytochrome $c$ derivative to measure electron transfer to the radical cation and oxyferryl heme in cytochrome c peroxidase. Biochemistry 35:1510715119

Wang J, Larsen RW, Moench SJ, Satterlee JD, Rousseau DL, Ondrias MR (1996b) Cytochrome c peroxidase complexed with cytochrome $c$ has an unperturbed heme moiety. Biochemistry $35: 453-463$

Witt H, Malatesta F, Nicoletti F, Brunori M, Ludwig B (1998) Tryptophan 121 of subunit II is the electron entry site to cytochrome-c oxidase in Paracoccus denitrificans. Involvement of a hydrophobic patch in the docking reaction. J Biol Chem 273:5132-5136

Worrall JAR, Kolczak U, Canters GW, Ubbink M (2001) Interaction of yeast iso-1-cytochrome c with cytochrome c peroxidase investigated by $[15 \mathrm{~N}, 1 \mathrm{H}]$ heteronuclear NMR spectroscopy. Biochemistry 40:7069-7076

Worrall JAR, Reinle W, Bernhardt R, Ubbink M (2003) Transient protein interactions studied by NMR spectroscopy: the case of cytochrome $c$ and adrenodoxin. Biochemistry 42:7068-7076 
Xu X, Reinle W, Hannemann F, Konarev PV, Svergun DI, Bernhardt R, Ubbink M (2008) Dynamics in a pure encounter complex of two proteins studied by solution scattering and paramagnetic NMR spectroscopy. J Am Chem Soc 130:6395-6403

Yonetani T, Ohnishi T (1966) Cytochrome c peroxidase, a mitochondrial enzyme of yeast. J Biol Chem 241:2983-2984

Yoshikawa S, Shinzawa-Itoh K, Nakashima R, Yaono R, Yamashita E, Inoue N, Yao M, Jie Fei M, Libeu CP, Mizushima T, Yamaguchi H, Tomizaki T, Tsukihara T (1998) Redox coupled crystal structural changes in bovine heart cytochrome c oxidase. Science 280:1723-1729

Yu C-A, Wen X, Xiao K, Xi D, Yu L (2002) Inter- and intra-molecular electron transfer in the cytochrome bc 1 complex. Biochem Biophys Acta 1555:65-70

Yu H, Lee I, Salomon AR, Yu K, Hüttemann M (2008) Mammalian liver cytochrome $\mathrm{c}$ is tyrosine48 phosphorylated in vivo, inhibiting mitochondrial respiration. Biochem Biophys Acta 1777:1066-1071

Zhao X, Leon IR, Bak S, Mogensen M, Wrzesinski K, Hojlund K, Jensen ON (2011) Phosphoproteome analysis of functional mitochondria isolated from resting human muscle reveals extensive phosphorylation of inner membrane protein complexes and enzymes. Mol Cell Proteomics M110.000299

Zhou JS, Hoffmann BM (1993) Cytochrome c peroxidase simultaneously binds cytochrome c at two different sites with strikingly different reactivities: titrating a "substrate" with an enzyme. J Am Chem Soc 115:11008-11009

Zhou JS, Hoffmann BM (1994) Stern-volmer in reverse: 2:1 stoichiometry of the cytochrome ccytochrome c peroxidase electron-transfer complex. Science 265:1693-1696

Zhu Y, Li M, Wang X, Jin H, Liu S, Xu J, Chen Q (2011) Caspase cleavage of cytochrome c 1 disrupts mitochondrial function and enhances cytochrome $c$ release. Cell Res. doi:10.1038/cr.2011.82 


\section{Figure captions}

Figure 1. Mapping of cytochrome $\mathrm{c}$ upon binding to its known targets. Cc interfacial residues are colored as follows: positively charged (blue), negatively charged (red), non-charged polar (yellow) and hydrophobic (brown). The heme group is marked in green and the non-interacting residues in gray. Two $180^{\circ}$-rotated surface representations (upper and lower) are depicted for each complex. The labels of the upper representations stand for the different Cc targets, and the technique used to define the $\mathrm{Cc}$ interface in each case is indicated between brackets. The horizontal rainbow-coded color bars represent the stability and lifetime of the complexes, from highly dynamic/transient (red) to more rigid/stable (blue). All mitochondrial complexes participate in ET reactions, while cytosolic adducts do not. Surface representations were generated from the structure of yeast Cc (PDB entry 1YCC, Louie and Brayer 1990), except those of the $\mathrm{Cc}-\mathrm{CcO}$ and $\mathrm{Cc}-\mathrm{Bcl}-\mathrm{xL}$ complexes (PDB entry 1J3S, Jeng et al. 2002), using Chimera (Pettersen et al. 2004)

Figure 2. Network of transient cytochrome $c$ interactions with its mitochondrial protein partners. The Cc partners are colored according to the functions ascribed to their interaction, as follows: Respiration chain in blue with Sco in green due to its dual role in assembling CuA of $\mathrm{CcO}$ and transferring electrons to $\mathrm{Cc} ; \mathrm{R}(\mathrm{N}) \mathrm{OS}$ metabolism in yellow; early apoptosis in gray; and the $\mathrm{Cb}$ 5-mediated nexus between mitochondrial membranes in purple. The dashed line for white-colored Adx stands for the non-physiological Cc-Adx interaction, in which $\mathrm{Cc}$ is used as a model of P450 in steroid hormone biosynthesis. Targets involved in ET and non-ET processes are represented by circles and squares, respectively. Double lines stand for $\mathrm{Cu}$ delivery from Sco to $\mathrm{CcO}$ and non-direct nexus between Erv1 and CcP through $\mathrm{R}(\mathrm{N}) \mathrm{OS}$ metabolism

Figure 3. Cytochrome c signalosome in mitochondria. The main Cc pathways at the IMS are shown. Dotted lines stand for ET pathways, whereas continuous lines represent the following events: binding to $\mathrm{Cc}$ partners, delivery of $\mathrm{Cu}$, activation of phosphorylated p66Shc and apoptosome, Cc post-translational modifications upon R(N)OS production, PTP opening, CLbinding of $\mathrm{Cc}$, and $\mathrm{Cc}$ translocation. The signaling pathways taking place under homeostatic conditions are colored in black, and those activated after apoptotic stimuli are in red. The Cc targets are colored using the same code as in Fig. 2. The asterisk highlights the electron flow between Sco and Cc, which has only been reported in bacteria (Banci et al. 2011b) but not in eukaryotic organisms 
Table 1

Binding dissociation constants and lifetimes of the complexes involving $\mathrm{Cc}$

\begin{tabular}{|c|c|c|c|}
\hline Cc complexes & $\mathbf{K}_{\mathrm{d}}(\boldsymbol{\mu M})$ & Lifetime (ms) & References \\
\hline $\mathrm{Cc}-\mathrm{CcP}$ & 5 & $<0.8$ & Worrall et al. (2001), Volkov et al. (2011) \\
\hline $\mathrm{Cc}-\mathrm{CcO}^{\mathrm{a}}$ & ND & $<1.5$ & Witt et al. (1998) \\
\hline $\mathrm{Adx}-\mathrm{Cc}$ & 25 & $<3$ & Worrall et al. (2003) \\
\hline $\mathrm{Cb}_{5}-\mathrm{Cc}$ & 20 & $<5.5$ & Volkov et al. (2005), Shao et al. (2003) \\
\hline $\mathrm{bc}_{1}-\mathrm{Cc}$ & ND & $<6.5$ & Nyola and Hunte (2008) \\
\hline $\mathrm{Cc}-\mathrm{CL}$ & ND & Stable $>3,000$ & Sinibaldi et al. (2010) \\
\hline $\mathrm{Bcl}-\mathrm{x}_{\mathrm{L}}-\mathrm{Cc}$ & 1,000 & ND & Bertini et al. (2011a) \\
\hline Cc-Apaf-1 & ND & Stable $>3,000$ & Acehan et al. (2002) \\
\hline
\end{tabular}

ND not determined

${ }^{a}$ Data corresponds to bacterial counterpart complexes 
Figure 1

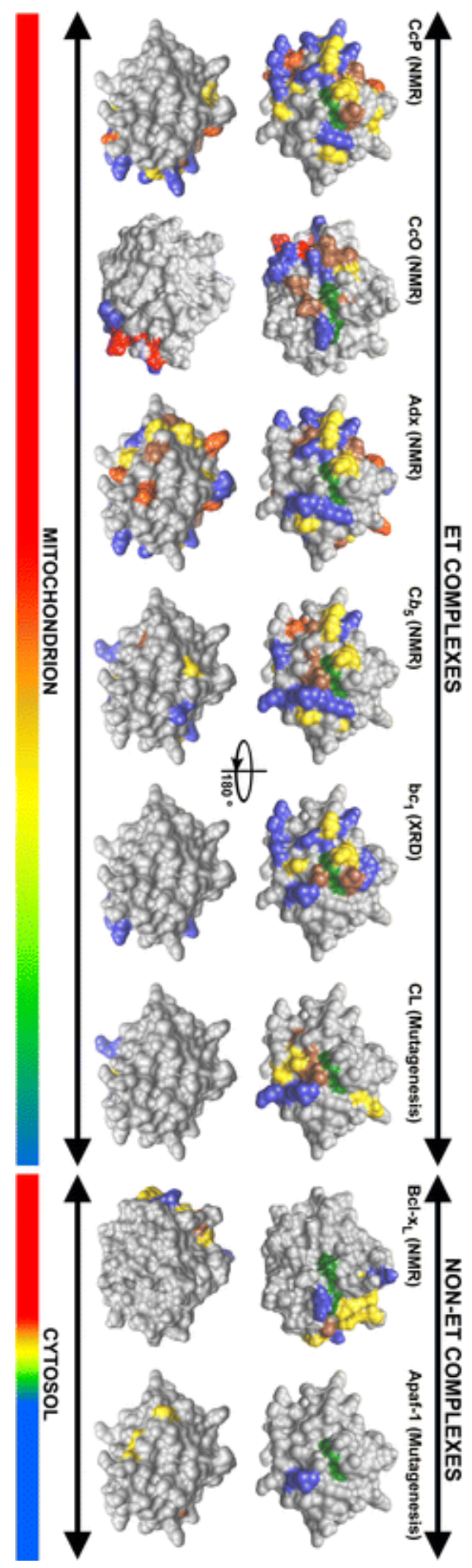


Figure 2

${ }^{a}$ Data corresponds to bacterial counterpart complexes

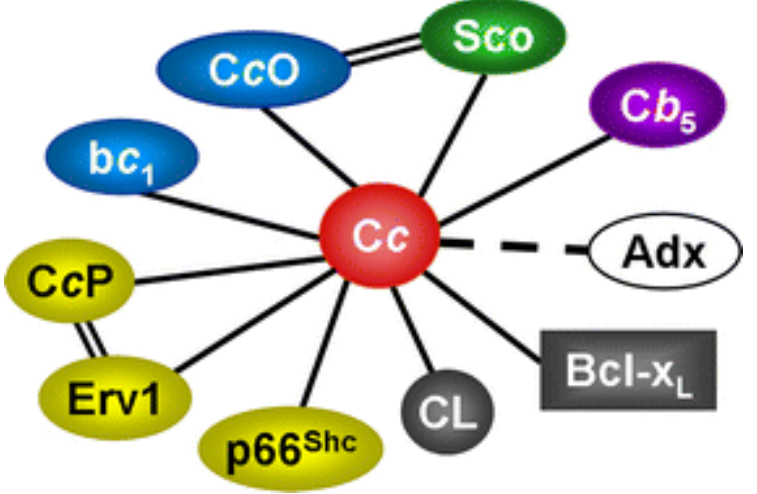


Figure 3

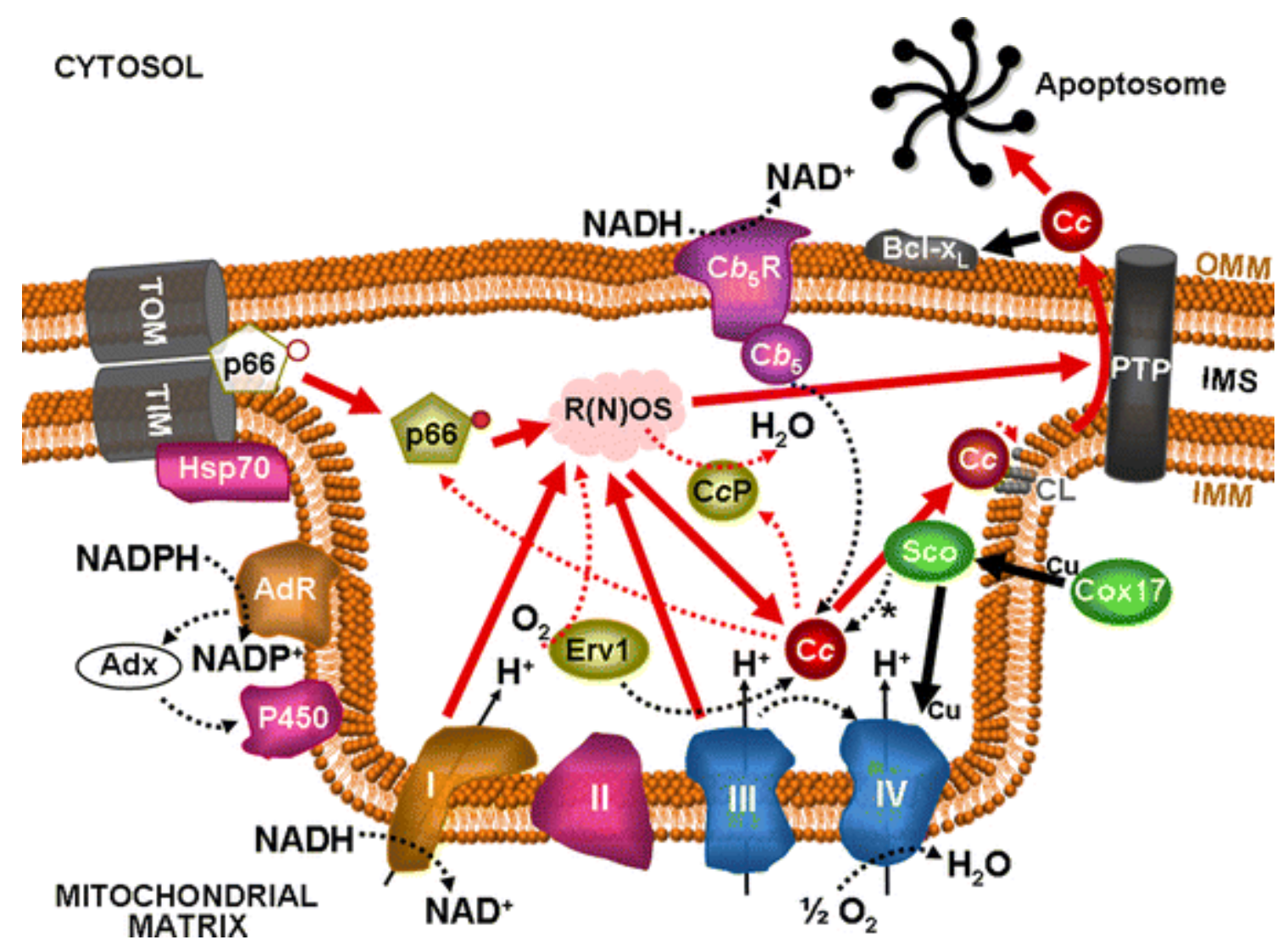

